\title{
Effect of caudal ketamine on minimum local anesthetic concentration of ropivacaine in children: A prospective randomized trial
}

Huai-Zhen Wang

Guangzhou Women and Children Medical Center

Ling-Yu Wang

Guangzhou Women and Children's Medical Center

Hui-Hong Liang

Guangzhou Women and Children's Medical Center

Yan-Ting Fan

Guangzhou Women and Children's Medical Center

Xing-Rong Song

Guangzhou Women and Children's Medical Center

Ying-Jun She ( $\nabla$ yjsheh@yeah.net )

Guangzhou Women and Children's Medical Center https://orcid.org/0000-0003-4222-9500

Research article

Keywords: anesthesia, caudal, ketamine, ropivacaine, analgesia, anesthetic techniques

Posted Date: January 2nd, 2020

DOI: https://doi.org/10.21203/rs.2.11369/v2

License: (9) (i) This work is licensed under a Creative Commons Attribution 4.0 International License.

Read Full License

Version of Record: A version of this preprint was published at BMC Anesthesiology on June 8th, 2020.

See the published version at https://doi.org/10.1186/s12871-020-01058-y. 


\section{Abstract}

Background: Caudal ketamine has been shown to provide an effective and prolonged post-operative analgesia with few adverse effects. However, the effect of caudal ketamine on the minimum local anesthetic concentration (MLAC) of ropivacaine for intra-operative analgesia is unclear.

Methods: One hundred and sixty-nine children were randomized to five groups: Group C (caudal ropivacaine only), Group K 0.25 (caudal ropivacaine plus $0.25 \mathrm{mg} / \mathrm{kg}$ ketamine), Group K 0.5 (caudal ropivacaine plus $0.5 \mathrm{mg} / \mathrm{kg}$ ketamine), Group K 0.75 (caudal ropivacaine plus $0.75 \mathrm{mg} / \mathrm{kg}$ ketamine), and Group K 1.0 (caudal ropivacaine plus $1.0 \mathrm{mg} / \mathrm{kg}$ ketamine). The primary outcome was the MLAC values of ropivacaine with/without ketamine for caudal block.

Results: The MLAC values of ropivacaine were $0.128 \%(0.028 \%)$ in the control group, $0.112 \%(0.021 \%)$ in Group K $0.25,0.112 \%(0.018 \%)$ in Group K $0.5,0.110 \%(0.019 \%)$ in Group K 0.75 , and $0.110 \%(0.020 \%)$ in Group K 1.0 . There were no significant differences among the five groups for the MLAC values $(p=0.11)$. During the post-operative period the mean durations of analgesia were $270,381,430,494$, and $591 \mathrm{~min}$ in the control, $\mathrm{K} 0.25, \mathrm{~K} 0.5, \mathrm{~K} 0.75$, and K 1.0 groups respectively, which shown significant differences among the five groups $(p<0.05)$.

Conclusions: Adding caudal ketamine to ropivacaine prolong the duration of post-operative analgesia; however, it does not decrease the MLAC of caudal ropivacaine for intra-operative analgesia in children.

\section{Background}

A caudal block is commonly used in children during lower abdominal and limb surgeries because it provides safe and effective perioperative analgesia. Single dose caudal levobupivacaine or ropivacaine provides analgesia for 4-8 hours and has gained popularity with a high success rate and a low incidence of adverse effects [1,2]. Also, it has been proved that several additives with local anesthetics can prolong the duration of caudal analgesia [3]. Research discovered that the most commonly used additives were clonidine (42.3\%), ketamine (37.5\%), opioids (18.1\%), adrenaline (1.8\%), and midazolam (0.3\%) [4].

Caudal block is usually injected by a single high-dose local anesthetic, while decreasing local anesthetic dose reduces local tissue and systemic toxicity. Adjuvants were usually used to decrease the dose of local anesthetic and prolong the duration of analgesia. The minimum local anesthetic concentration (MLAC) has been conventionally used for evaluating the relative efficacy of generally used local anesthetics [5-7]. Many additives have been administrated in order to decrease the concentration of local anesthetics for caudal analgesia, while the effect of some additives on the MLAC values of local anesthetics have been explored in some previous studies [8, 9]. Caudal clonidine and dexmedetomidine produced a local anesthetic sparing effect with a dose-dependent decrease in MLAC of levobupivacaine for caudal anesthesia $[8,9]$. As a commonly used additive, caudal ketamine has been shown to provide an effective and prolonged post-operative analgesia with few adverse events. However, the effect of caudal ketamine on the MLAC of ropivacaine is unclear. The aim of this prospective, randomized, and 
double-blind trial was to observe whether ketamine reduces the MLAC of ropivacaine for caudal block in children.

\section{Methods}

This study was approved by the Institutional Review Board of Guangzhou Women and Children's Medical Center (IRB2013053103), and written informed patient consent was attained from the parents or legal guardians of each paediatric patient in this trial. The trial was registered prior to patient enrolment at chictr.org.cn (ChiCTR-TRC-13003492). One hundred and sixty nine ASA physical status I or II children aged from 1 to 3 years old scheduled to undergo elective hydrocele or inguinal hernia repair were recruited. Exclusion criteria included patients with neurological, psychiatric, cardiovascular, respiratory, hepatic, renal diseases or bleeding disorders; or a known allergy history of anesthetics. Using a computergenerated table and a sealed envelope with sequence of numbers, children were randomly allocated into five groups into one of the five groups: Group C (caudal ropivacaine only), Group $\mathrm{K}_{0.25}$ (caudal ropivacaine plus $0.25 \mathrm{mg} / \mathrm{ml}$ preservative free ketamine), Group $\mathrm{K}_{0.5}$ (caudal ropivacaine plus $0.5 \mathrm{mg} / \mathrm{ml}$ preservative free ketamine), Group $\mathrm{K}_{0.75}$ (caudal ropivacaine plus $0.75 \mathrm{mg} / \mathrm{ml}$ preservative free ketamine), and Group $\mathrm{K}_{1.0}$ (caudal ropivacaine plus $1.0 \mathrm{mg} / \mathrm{ml}$ preservative free ketamine). The total volume of ropivacaine with/without preservative free ketamine solution for caudal injection in all groups are 1 $\mathrm{ml} / \mathrm{kg}$.

All children underwent preoperative fasting for 6 hours and received no premedication. Sevoflurane via a face mask was used for anesthesia induction in the children. After securing intravenous access, $3 \mathrm{mg} / \mathrm{kg}$ propofol was intravenously administered to maintain sedation in a single dose or repeated doses. A caudal puncture was performed with a 22-gauge catheter by introducing in the caudal space with the patient in the left lateral decubitus position by a consultant anesthesiologist. The mixed solution of caudal injection is prepared by $0.9 \%$ saline, ropivacaine and ketamine. After felling the loss of resistance and checking for the negative presence of cerebrospinal fluid or blood, the ropivacaine with/without preservative free ketamine solution (total volume, $1 \mathrm{ml} / \mathrm{kg}$ ) was administered via the catheter over $60 \mathrm{~s}$. All inhalational agents were discontinued after the finish of the caudal injection. Then the patient was repositioned to supine for surgery. Continuously intravenous infused propofol (8-10 mg/kg/h) was administered to maintain sedation, and the depth of anesthesia was adjusted accordingly with the objective of achieving $80-120 \%$ baseline non-invasive mean arterial pressure. Dermatomal heights or upper limits of the caudal block were not formally assessed by pinprick before skin incision which was performed at exactly 20 minutes after the caudal injection. Baseline vital signs were collected to ensure a stable state and to discriminate slow onset of analgesia which was regarded as a confounding variable. An anesthesiologist who was unaware of the group assignments and the test concentrations of ropivacaine or ketamine collected the data and evaluated analgesic efficacy. After skin incision, the patient was observed for at least 60 seconds for hemodynamic stability and signs of purposeful movement. 
The primary outcome was the MLAC of ropivacaine with/without ketamine for caudal block in children. The success of a caudal block was defined as the change in hemodynamic parameters $<20 \%$ of baseline values and the absence of gross purposeful movement after skin incision. The modified Dixon's up-anddown method was used to determine the target concentration of caudal ropivacaine for each pediatric patient, starting from $0.16 \%$ in each group, with $0.02 \%$ as a step size. According to the response of the previous patient in the same group, the target concentration of caudal ropivacaine was increased or decreased. If it failed, a $0.02 \%$ concentration of caudal ropivacaine would be increased for the next patient. If it was successful, the next child could be given caudal ropivacaine where the concentration would be decreased by $0.02 \%$. When a response was determined to be a failure, the surgeon would stop all operations, and a rescue dose of $0.5 \mathrm{mg} / \mathrm{kg}$ ketamine would be intravenously administrated immediately to reduce the pain and could be repeated if needed during the surgery. A pair of crossover was defined as the midpoint between failed and successful caudal block in two consecutive children. And the study would be ended after collecting nine pairs of crossover in each group.

The secondary outcomes of the study were durations of analgesia. Postoperative analgesia was assessed by using the "Face, Legs, Activity, Cry, Consoling" tool (FLACC). A FLACC score of more than 4 points was considered as inadequate analgesia and was additional orally administrated $10 \mathrm{mg} / \mathrm{kg}$ ibuprofen every 6 hour as needed. The duration time of analgesia was defined from caudal block to the first postoperative rescue analgesia. An independent nurse evaluated the pain scale every hour in 8 hours after the surgery and then every 6 hour as required. Side effects like postoperative nausea and vomiting (PONV), urine retention, agitation, hypotension, bradycardia, and respiratory depression were recorded. Emergence agitation evaluation was scored by using a five-point scale. A score of $\geq 3$ was defined as emergence agitation according to five-point scale ( $0=$ falling asleep peacefully; $1=$ quiet; $2=$ easy to console; $3=$ difficult to console with moderate agitation; $4=$ combative, excited, and disorientated). On the second day after surgery all children were discharged.

\section{Statistical analysis}

Statistical analyses were performed in SPSS 19.0 for Windows (SPSS Inc., USA). Data were expressed as mean (SD) or count, when appropriate. The MLAC was estimated from the up-and-down sequences with the Dixon and Massey method. The MLAC of caudal ropivacaine was analysed by calculating the midpoint concentration of all independent pairs of crossover points in each group. According to the study conducted by Paul and Fisher [10], nine pairs of crossover patients were needed. The variance of age, weight, duration of surgery, propofol doses and recovery time was analysed by using analysis of variance followed by a Dunnet $t$ test or Kruskal-Wallis test. The type of surgery and adverse effects were analysed with the Chi-square test. The duration of caudal analgesia was analysed with Kaplan-Meier survival analysis and log-rank test. $P<0.05$ was considered statistically significant.

\section{Results}


One hundred and eighty-one children were enrolled in this study, 169 were analysed and 12 were excluded. Among the excluded patients, four were excluded because of serious airway symptoms, two were excluded because of data loss, three declined to participate in the study, and three were excluded due to the violation of anesthesia. All caudal block were considered as successful. The CONSORT flow diagram shows the details of patient recruitment (Figure 1). Patient characteristics, the duration of operation, and the type of surgery were shown in Table 1. There were no significantly difference in incidences of agitation, urine retention, respiratory depression, bradycardia, hypotension, and PONV among groups (Table 1).

The patient responses to the skin incision according to the up-and-down sequence were illustrated in Figure 2. The MLAC values of ropivacaine were $0.128 \%(0.028 \%)$ in control group, $0.112 \%(0.021 \%)$ in Group $\mathrm{K}_{0.25}, 0.112 \%(0.018 \%)$ in Group $\mathrm{K}_{0.5}, 0.110 \%$ (0.019\%) in Group $\mathrm{K}_{0.75}$, and $0.110 \%(0.020 \%)$ in Group $\mathrm{K}_{1.0}$. There were no significant differences of the MLAC values among the five groups $(p=0.11)$.

The durations of analgesia in the five groups were illustrated with Kaplan-Meier survival curves in Figure 3. The mean durations of analgesia in the postoperative period were 270, 381, 430, 494, and 591 min in the control, $\mathrm{K}_{0.25}, \mathrm{~K}_{0.5}, \mathrm{~K}_{0.75}$, and $\mathrm{K}_{1.0}$ groups, respectively. There were significant differences among the five groups (control VS $\mathrm{K}_{0.25}$, control VS $\mathrm{K}_{0.5}$, control VS $\mathrm{K}_{0.75}$, and control VS $\mathrm{K}_{1.0}, \mathrm{p}<0.01$ ).

\section{Discussion}

The aim of this study was to demonstrate whether caudal ketamine reduces the MLAC of caudal ropivacaine and prolongs the duration of post-operative analgesia in children. Our results showed that combined ketamine with ropivacaine for caudal block would prolong the duration of post-operative analgesia. However, caudal ketamine did not reduce the MLAC of caudal ropivacaine for intra-operative analgesia in children.

Some studies have determined the MLAC value of ropivacaine for caudal blocks in young children. Ingelmo et al. [7] investigated the MLAC of a single dose of caudal ropivacaine with 1 MAC of sevoflurane in children aged 1-6 years old冈and the MLAC of caudal ropivacaine was $0.066 \%$. Deng et al. $[5,11]$ reported that the MLAC of caudal ropivacaine with 0.5 MAC enflurane was $0.11 \%$ in children aged $1-5$ years old, and it was $0.107 \%$ in preschool age children with 0.7 MAC sevoflurane. The MLAC values of ropivacaine were $0.128 \%$ in the present study, and the value reported in our study was consistent with the value reported elsewhere, but it was different from certain other studies. This discrepancy could be mainly attributed to individual factors, the concentration and volume of caudal injection, the use and concentration of inhaled or intravenous anesthetics, methods of measuring $\operatorname{MLAC}$ value $[9,10]$. Sevoflurane have a much stronger inhibitory effect compared with propofol within concentrations close to their reported $50 \%$ effective concentrations $[12,13]$. And sevoflurane strongly decrease the required concentrations of local anesthetics compared with midazolam or propofol. Also, MLAC estimates could be influenced by starting concentration, number of crossovers, increment size of concentration when using up-down method for analysis of quantal data [10]. 
Lots of previous studies had performed to evaluate the effect of different doses of ketamine on the postoperative analgesia. However, to the best of our knowledge, no Chinese or English studies have been designed to evaluate the effect of different dose of caudal ketamine on MLAC of ropivacaine. Our results showed that caudal ketamine did not influence the MLAC of ropivacaine for intra-operative caudal analgesia in young children. However, it prolonged the duration of postoperative analgesia in this study. Our results were consistent with previous studies of caudal ketamine in association with local anesthetics for post-operative analgesia [14-17]. Our results showed that caudal ketamine prolonged the duration of post-operative analgesia in a dose-dependent manner. Caudal ketamine with $0.25 \%$ bupivacaine was used in doses of $0.25,0.5$, and $1 \mathrm{mg} / \mathrm{kg}$, obtaining mean postoperative analgesia durations of $7.9,11$, and $16.5 \mathrm{~h}$, respectively [18]. In another study, the mean durations of caudal analgesia in caudal $0.25 \%$ bupivacaine with $0.25,0.5,1 \mathrm{mg} / \mathrm{kg}$ ketamine were $8.8,22.1$, and $25.2 \mathrm{~h}$, respectively [19]. Adequate postoperative analgesia has also been achieved by combining caudal ropivacaine with ketamine. Adding $0.25 \mathrm{mg} / \mathrm{kg}$ ketamine to $0.2 \%$ ropivacaine provided analgesia up to 9 $\mathrm{h}$ in Lee et al. study [14]. Adding $0.5 \mathrm{mg} / \mathrm{kg}$ ketamine to $0.2 \%$ ropivacaine produced analgesia that extended about 11-17 h [15-17].

Caudal ketamine provide analgesia of central nervous system effects by both a direct effect on the spinal cord and a systemic absorption effect. Ketamine exerts its analgesic and anesthetic effects by binding to a subset of glutamate receptors influenced by the agonist N-methyl-D-asparate (NMDA). Caudal ketamine proudced analgesic effects by acting on NMDA receptors in the lumbar spinal cord, or from $\mu$-opioid receptors agonist activity and interaction with voltage-sensitive sodium channels [20,21]. Koinig et al. [22] showed that the mean time to maximum ketamine plasma concentration after caudal ketamine administration was about 20 min and the maximum ketamine plasma concentrations after caudal injection were significantly lower than that after intramuscular administration of ketamine. Caudal ketamine alone was typically used to provide post-operative analgesia in children in several studies [23, 24]. These suggested that caudal ketamine analgesic effect was provided primarily by a direct effect on the spinal cord. In our study, skin incision was performed at $20 \mathrm{~min}$ after caudal injection. And at this time, it was the peak of ketamine plasma concentration, may not be the peak of ketamine concentration in the spinal cord nervous after caudal ketamine injection. It's the limitation in our study and future studies need to confirm this.

Ketamine is a low molecular weight and relatively high lipid soluble drug, and this characteristic of ketamine leads to release slowly from the lipid composition of the spinal cord [25]. Elimination half-life after epidurally administered ketamine was two times longer than that after intravenous ketamine [26]. Hence, the synergistic effect between ketamine and ropivacaine primarily resulted in the prolongation of post-operative caudal analgesia, but not for intra-operative caudal analgesia. The doses of caudal ketamine were from 0 to $1 \mathrm{mg} / \mathrm{kg}$ in the present study. This study's limitation is that we're not sure whether ketamine in larger doses than $1 \mathrm{mg} / \mathrm{kg}$ could decrease the MLAC of ropivacaine for intraoperative caudal analgesia in children. However, the range of doses in our study is representative of commonly used doses in clinical medicine. 


\section{Conclusions}

In summary, this study indicated that the addition of caudal ketamine ranged from 0 to $1 \mathrm{mg} / \mathrm{kg}$ to ropivacaine prolonged the duration of post-operative analgesia; however, it did not decrease the MLAC of caudal ropivacaine for intra-operative analgesia in children.

\section{Abbreviations}

FLACC : Face, Legs, Activity, Cry, Consoling" tool; PONV: Postoperative Nausea and Vomiting; MLAC: Minimum Local Anesthetic Concentration; ASA: American Society of Anesthesiology;

NMDA : N-methyl-D-asparate; MAC: Minimal Alveolar Concentration

\section{Declarations}

\section{Acknowledgement}

The authors would like to thank the staff of anesthesia nurses at the Department of Anesthesiology and Perioperative Medicine, Guangzhou Women and Children Medical Centre.

\section{Funding}

This study was supported by Guangzhou Institute of Paediatrics, Guangzhou Women and Children's Medical Centre, Guangzhou, China (NO. YIP-2016-005).

\section{Availability of data and materials}

The datasets are not publicly available, but available from the corresponding author on reasonable request.

\section{Authors' contributions}

All authors have read and approved the manuscript. WHZ: Study design, data analysis, writing paper and approval of final manuscript. WLY: data analysis, writing paper and approval of final manuscript. LHH: Study design, data collection and approval of final manuscript. FYT: Study design, data collection, data analysis, manuscript revision and approval of final manuscript. SXR: Study design, manuscript revision and approval of final manuscript. SYJ: Study design, data analysis, writing paper, manuscript revision and approval of final manuscript.

\section{Ethics approval and consent to participate}

Ethical approval for Institutional Review Board of Guangzhou Women and Children's Medical Center (IRB2013053103) and registered in the Chinese Clinical Trial Registry (ChiCTR-TRC-13003492, date of 
registration: 2013-8-13) prior to patient enrollment. Written informed consent was obtained from the parents or legal guardians of each paediatric patient in the study.

Consent for publication

Not applicable.

Competing interests:

The authors declare that they have no competing interests.

Publisher's Note

Springer Nature remains neutral with regard to jurisdictional claims in published maps and institutional affiliations

\section{References}

1. Locatelli B, Ingelmo P, Sonzogni V, Zanella A, Gatti V, Spotti A, Di Marco S, Fumagalli R: Randomized, double-blind, phase III, controlled trial comparing levobupivacaine $0.25 \%$, ropivacaine $0.25 \%$ and bupivacaine $0.25 \%$ by the caudal route in children. British journal of anaesthesia 2005, 94(3):366371.

2. Kim EM, Lee JR, Koo BN, Im YJ, Oh HJ, Lee JH: Analgesic efficacy of caudal dexamethasone combined with ropivacaine in children undergoing orchiopexy. British journal of anaesthesia 2014, 112(5):885-891.

3. Ansermino M, Basu R, Vandebeek C, Montgomery C: Nonopioid additives to local anaesthetics for caudal blockade in children: a systematic review. Paediatric anaesthesia 2003, 13(7):561-573.

4. Menzies R, Congreve K, Herodes V, Berg S, Mason DG: A survey of pediatric caudal extradural anesthesia practice. Paediatric anaesthesia 2009, 19(9):829-836.

5. Deng XM, Xiao WJ, Tang GZ, Luo MP, Xu KL: Minimum local analgesic concentration of ropivacaine for intra-operative caudal analgesia in pre-school and school age children. Anaesthesia 2010, 65(10):991-995.

6. McLeod GA, Dale J, Robinson D, Checketts M, Columb MO, Luck J, Wigderowitz C, Rowley D: Determination of the EC50 of levobupivacaine for femoral and sciatic perineural infusion after total knee arthroplasty. British journal of anaesthesia 2009, 102(4):528-533.

7. Ingelmo P, Frawley G, Astuto M, Duffy C, Donath S, Disma N, Rosano G, Fumagalli R, Gullo A: Relative analgesic potencies of levobupivacaine and ropivacaine for caudal anesthesia in children. Anesthesia and analgesia 2009, 108(3):805-813.

8. Disma N, Frawley G, Mameli L, Pistorio A, Alberighi OD, Montobbio G, Tuo P: Effect of epidural clonidine on minimum local anesthetic concentration (ED50) of levobupivacaine for caudal block in children. Paediatric anaesthesia 2011, 21(2):128-135. 
9. She YJ, Zhang ZY, Song XR: Caudal dexmedetomidine decreases the required concentration of levobupivacaine for caudal block in pediatric patients: a randomized trial. Paediatric anaesthesia 2013, 23(12):1205-1212.

10. Paul M, Fisher DM: Are estimates of MAC reliable? Anesthesiology 2001, 95(6):1362-1370.

11. Deng XM, Xiao WJ, Tang GZ, Luo MP, Xu KL: The minimum local anesthetic concentration of ropivacaine for caudal analgesia in children. Anesthesia and analgesia 2002, 94(6):1465-1468, table of contents.

12. Matute E, Rivera-Arconada I, Lopez-Garcia JA: Effects of propofol and sevoflurane on the excitability of rat spinal motoneurones and nociceptive reflexes in vitro. British journal of anaesthesia 2004, 93(3):422-427.

13. Kammer T, Rehberg B, Menne D, Wartenberg HC, Wenningmann I, Urban BW: Propofol and sevoflurane in subanesthetic concentrations act preferentially on the spinal cord: evidence from multimodal electrophysiological assessment. Anesthesiology 2002, 97(6):1416-1425.

14. Lee HM, Sanders GM: Caudal ropivacaine and ketamine for postoperative analgesia in children. Anaesthesia 2000, 55(8):806-810.

15. De Negri P, Ivani G, Visconti C, De Vivo P: How to prolong postoperative analgesia after caudal anaesthesia with ropivacaine in children: S-ketamine versus clonidine. Paediatric anaesthesia 2001, 11(6):679-683.

16. Akbas M, Titiz TA, Ertugrul F, Akbas H, Melikoglu M: Comparison of the effect of ketamine added to bupivacaine and ropivacaine, on stress hormone levels and the duration of caudal analgesia. Acta anaesthesiologica Scandinavica 2005, 49(10):1520-1526.

17. Odes R, Erhan OL, Demirci M, Goksu H: Effects of ketamine added to ropivacaine in pediatric caudal block. Agri : Agri 2010, 22(2):53-60.

18. Semple D, Findlow D, Aldridge LM, Doyle E: The optimal dose of ketamine for caudal epidural blockade in children. Anaesthesia 1996, 51(12):1170-1172.

19. Panjabi N, Prakash S, Gupta P, Gogia AR: Efficacy of three doses of ketamine with bupivacaine for caudal analgesia in pediatric inguinal herniotomy. Regional anesthesia and pain medicine 2004, 29(1):28-31.

20. Coggeshall RE, Carlton SM: Receptor localization in the mammalian dorsal horn and primary afferent neurons. Brain research Brain research reviews 1997, 24(1):28-66.

21. Hirota K, Lambert DG: Ketamine: its mechanism(s) of action and unusual clinical uses. British journal of anaesthesia 1996, 77(4):441-444.

22. Koinig H, Marhofer P, Krenn CG, Klimscha W, Wildling E, Erlacher W, Nikolic A, Turnheim K, Semsroth M: Analgesic effects of caudal and intramuscular S(+)-ketamine in children. Anesthesiology 2000, 93(4):976-980.

23. Almenrader N, Passariello M, D'Amico G, Haiberger R, Pietropaoli P: Caudal additives for postoperative pain management in children: $\mathbf{S ( + ) - k e t a m i n e ~ a n d ~ n e o s t i g m i n e . ~ P a e d i a t r i c ~ a n a e s t h e s i a ~}$ 2005, 15(2):143-147. 
24. Passariello M, Almenrader N, Canneti $A$, Rubeo $L$, Haiberger $R$, Pietropaoli $P$ : Caudal analgesia in children: S(+)-ketamine vs S(+)-ketamine plus clonidine. Paediatric anaesthesia 2004, 14(10):851855 .

25. Xie H, Wang X, Liu G, Wang G: Analgesic effects and pharmacokinetics of a low dose of ketamine preoperatively administered epidurally or intravenously. Clin J Pain 2003, 19(5):317-322.

26. Pedraz JL, Lanao JM, Calvo MB, Muriel C, Hernandez-Arbeiza J, Dominguez-Gil A: Pharmacokinetic and clinical evaluation of ketamine administered by i.v. and epidural routes. International journal of clinical pharmacology, therapy, and toxicology 1987, 25(2):77-80.

\section{Tables}

Table 1 Children's demographic and experimental data and postoperative side effects data 


\begin{tabular}{|c|c|c|c|c|c|c|}
\hline Group & Group C & Group $\mathrm{K}_{0.25}$ & Group $\mathrm{K}_{0.5}$ & Group $\mathrm{K}_{0.75}$ & Group $\mathrm{K}_{1.0}$ & $\mathrm{P}$ \\
\hline Number of Patients (n) & 32 & 31 & 34 & 34 & 38 & / \\
\hline Age (months) & $22(7)$ & $20(7)$ & $21(7)$ & $19(6)$ & $20(7)$ & 0.653 \\
\hline Weight (kg) & $11.6(1.6)$ & $11.3(1.6)$ & $11.8(1.7)$ & $11.4(1.7)$ & $11.3(1.8)$ & 0.737 \\
\hline Duration of surgery (min) & $32(9)$ & $30(7)$ & $29(5)$ & $29(6)$ & $30(8)$ & 0.378 \\
\hline Recovery time (min) & $31(4)$ & $31(8)$ & $31(3)$ & $30(6)$ & $30(7)$ & 0.850 \\
\hline Propofol dose (mg) & $105(27)$ & 104(26) & 107(30) & 103(28) & 102(28) & 0.957 \\
\hline \multicolumn{7}{|l|}{ Type of surgery } \\
\hline & & & & & & 0.96 \\
\hline Inguinal hernia $(n)$ & 22 & 23 & 24 & 26 & 27 & \\
\hline Hydrocele (n) & 10 & 8 & 10 & 8 & 11 & \\
\hline PONV (n) & 4 & 4 & 5 & 6 & 10 & 0.513 \\
\hline Agitation (n) & 0 & 0 & 0 & 0 & 0 & / \\
\hline Urine retention $(n)$ & 1 & 0 & 0 & 0 & 0 & 0.366 \\
\hline Bradycardia (n) & 1 & 1 & 2 & 1 & 3 & 0.822 \\
\hline Hypotension (n) & 0 & 1 & 0 & 1 & 0 & 0.517 \\
\hline Respiratory depression (n) & 0 & 0 & 0 & 0 & 0 & / \\
\hline
\end{tabular}

Values are mean (SD) or numbers, Data are mean \pm SD or numbers of cases $(n)$.

Figures 


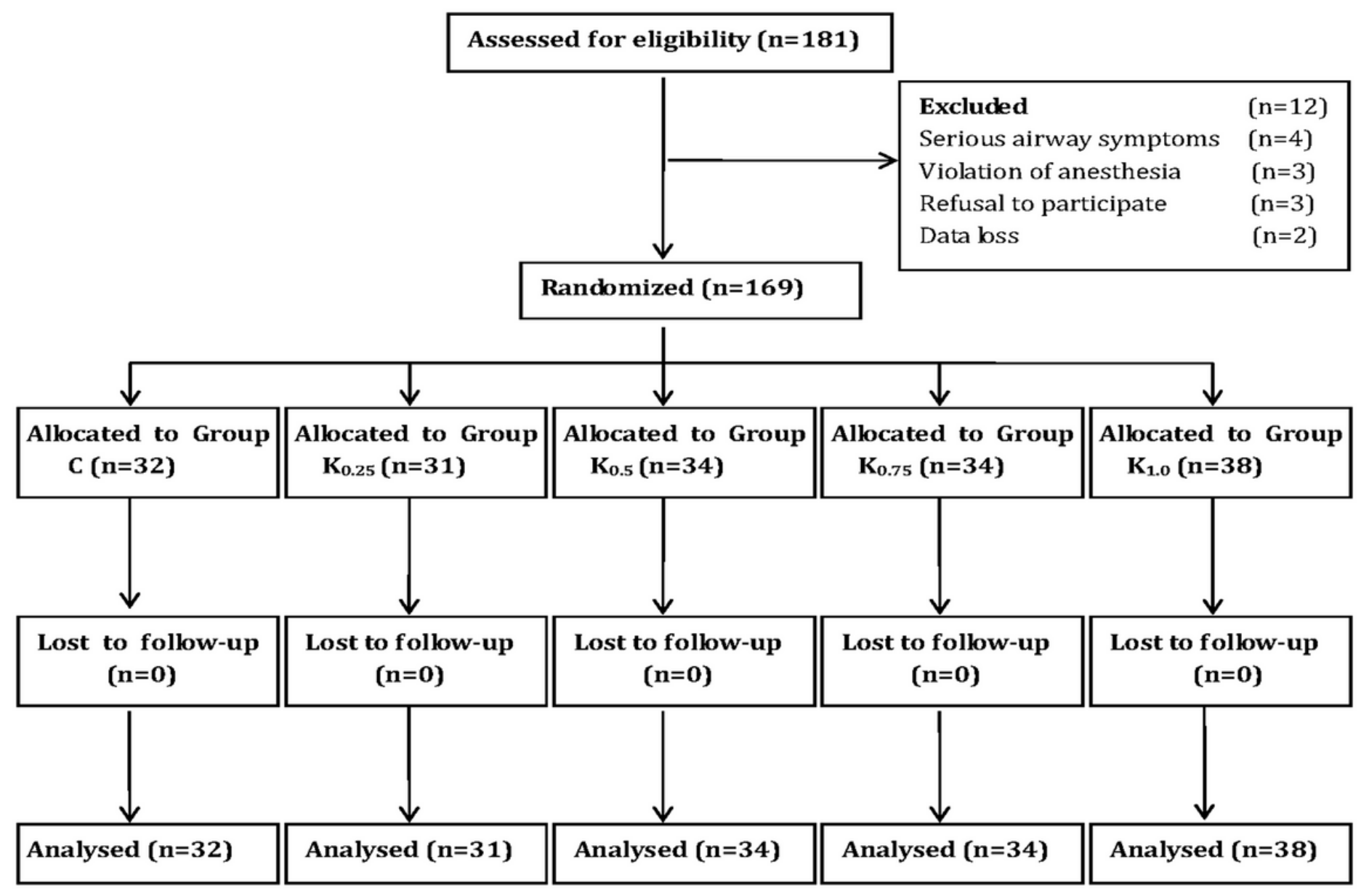

Figure 1

Consort flow diagram. 

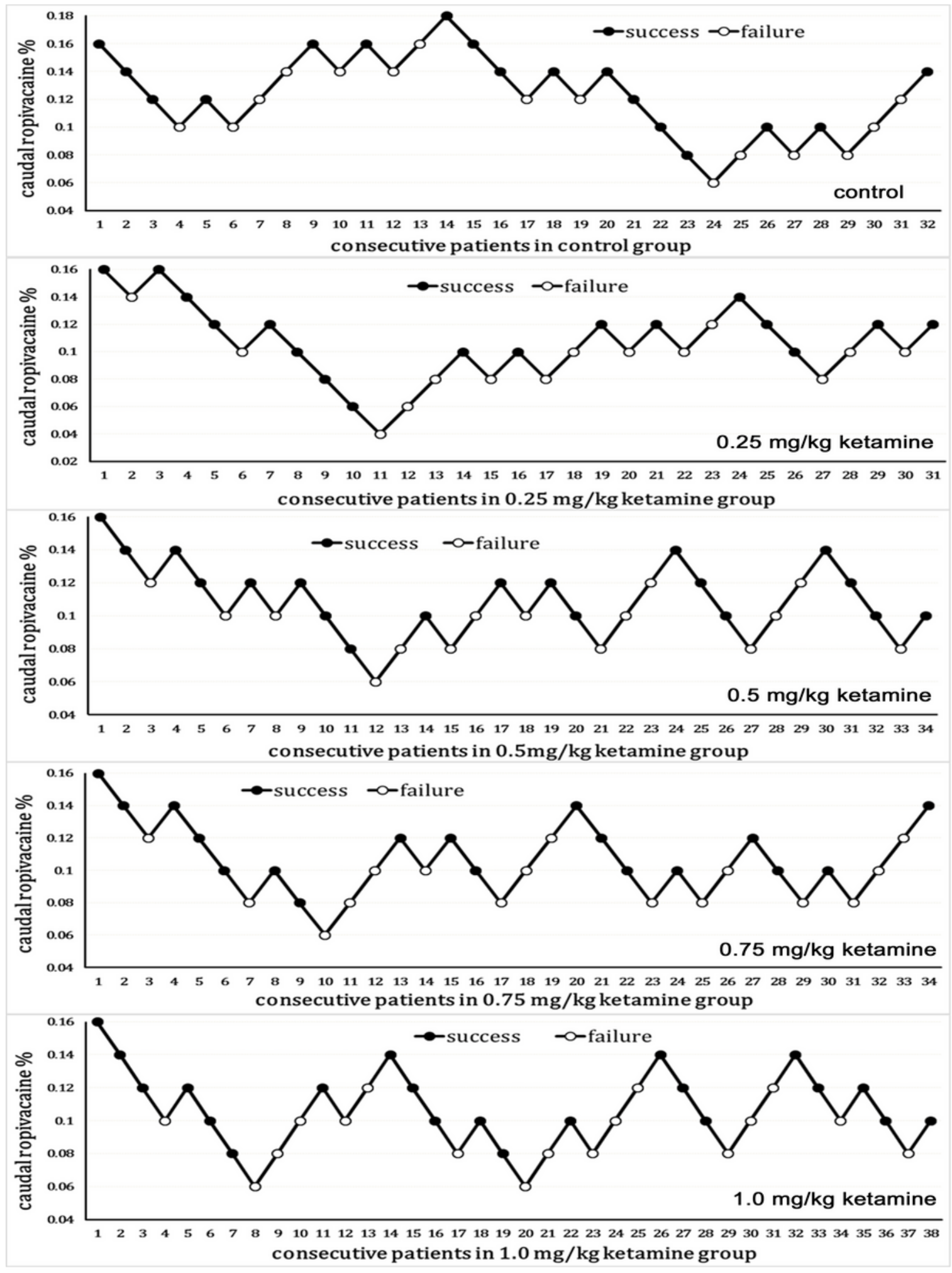

\section{Figure 2}

The response curve of consecutive children in each of the five groups. Skin incisions were attempted at different concentrations of caudal ropivacaine. The MLAC values of ropivacaine were $0.128 \%(0.03 \%)$ in the control group, $0.112 \%(0.02 \%)$ in Group K0.25, $0.112 \%(0.02 \%)$ in Group K0.5, $0.110 \%(0.02 \%)$ in Group K0.75, and $0.110 \%(0.02 \%)$ in Group K1.0. There were no significant differences among the five groups for the MLAC values $(p=0.11)$. 


\section{Survival functions}

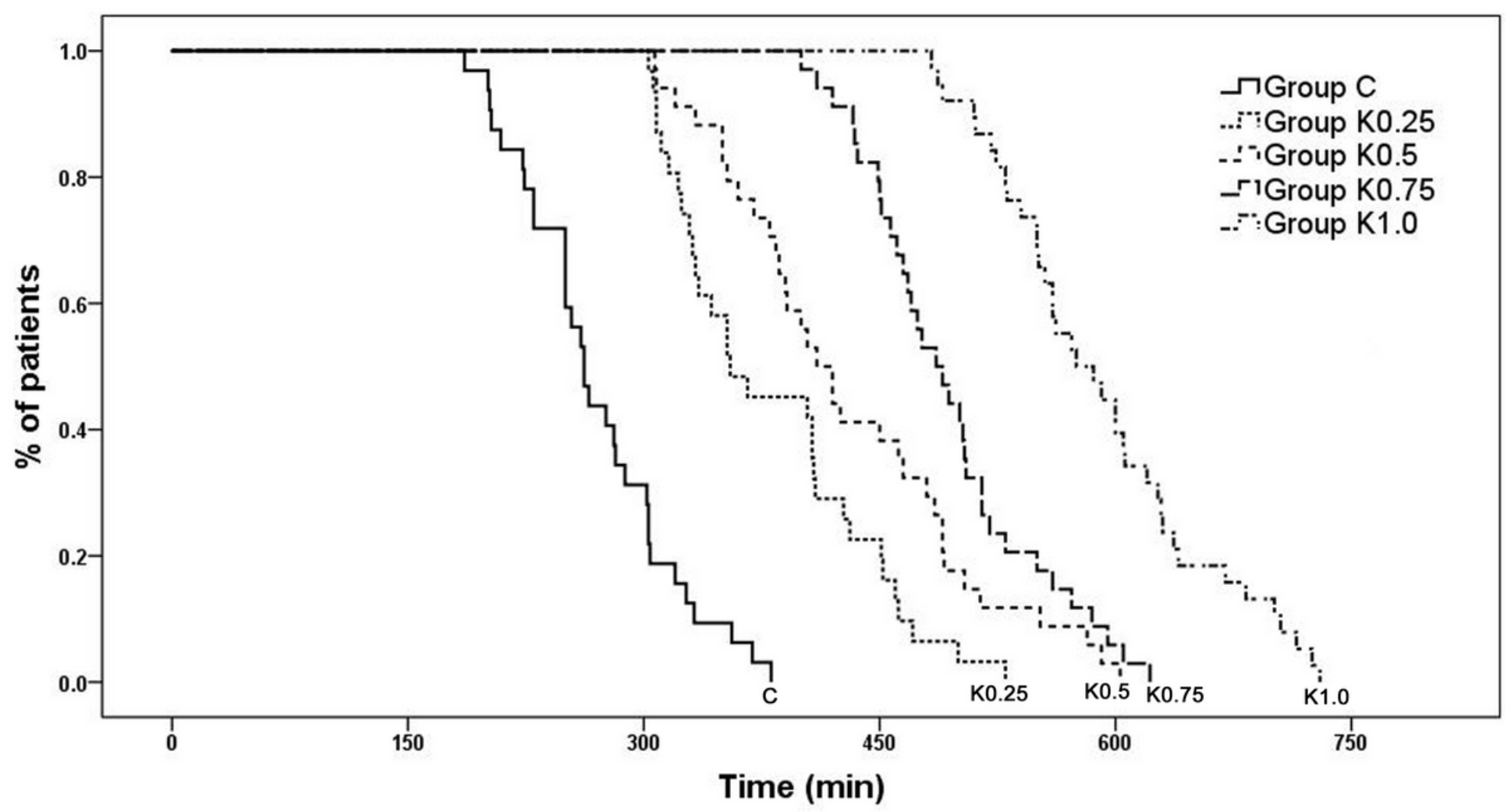

Figure 3

Results of Kaplan-Meier survival analysis were displayed as survival curves for the five caudal solution. The log-rank test was used to compare the rate of requirement for additional analgesia in the study.

\section{Supplementary Files}

This is a list of supplementary files associated with this preprint. Click to download.

- CONSORT2010Checklist.doc 